\title{
Title:
}

\section{Citizen science, animal behaviour and digital devices: challenges and solutions}

\author{
First Author ${ }^{1}$ \\ Didone Frigerio \\ Affiliation \\ University of Vienna, Konrad Lorenz Research Centre, Core Facility for Behaviour and Cognition, and \\ Department of Behavioural and Cognitive Biology \\ Address, Country \\ Fischerau 11, A-4645 Gruenau im Almtal, Austria \\ E-mail: didone.frigeriodunivie.ac.at
}

\section{Another Author}

\section{Verena Puehringer-Sturmayr}

Affiliation

University of Vienna, Konrad Lorenz Research Centre, Core Facility for Behaviour and Cognition, and Department of Behavioural and Cognitive Biology

Address, Country

Fischerau 11, A-4645 Gruenau im Almtal, Austria

E-mail: verena.puehringer-sturmayr@univie.ac.at

\section{Another Author}

\section{Christiane Steinbacher}

Affiliation

University of Vienna, Konrad Lorenz Research Centre, Core Facility for Behaviour and Cognition Address, Country

Fischerau 11, A-4645 Gruenau im Almtal, Austria

E-mail: c.steinbacheregmx.at

\section{Another Author}

Julia Rittenschober

${ }^{1}$ Speaker 
Affiliation

University of Vienna, Konrad Lorenz Research Centre, Core Facility for Behaviour and Cognition

Address, Country

Fischerau 11, A-4645 Gruenau im Almtal, Austria

E-mail: julia.rittenschober@yahoo.de

\section{Another Author}

\section{Sonia Kleindorfer}

Affiliation

University of Vienna, Konrad Lorenz Research Centre, Core Facility for Behaviour and Cognition, and Department of Behavioural and Cognitive Biology

Address, Country

Fischerau 11, A-4645 Gruenau im Almtal, Austria

E-mail: sonia.kleindorfer@univie.ac.at

Here you can write the abstract for your paper.

Actively involving citizens in research allows current challenges to be met in a more effective way and ideally in line with the expectations of the society. In the present study, we discuss challenges and solutions when involving volunteers in the data collection of behavioural patterns of three model avian species by using a digital application developed for ad hoc observations.

Keywords: citizen science, animal behaviour, reliability, digital devices

Short title: Citizen science, animal behaviour and digital devices

5th Austrian Citizen Science Conference 2019 (ACSC2019)

26-28, June, 2019

Obergurgl, Austria 


\section{Introduction}

Actively involving the civil society in research processes allows current challenges to be met in a more effective way that ideally also align with the expectations of the society. In this light, citizen science programs help to establish partnerships between members of the scientific and societal community that generate knowledge, foster scientific literacy and enhance learning through engagement [1]. Yet, in order to generate a win-win situation for all participants, it is important that scientists address citizen scientists, volunteers and the general public in an understandable and memorable manner. Therefore, communication and the choice of adequate tools play an essential role in the implementation of citizen science activities. The wide range of available tools, from "analogue" to "digital", are supposed to ease the implementation of a specific research question. Finding and developing the right method, however, is rather the result of several 'trial and error' attempts and the success also depends on the characteristics (age, motivation) of the participating citizen scientists [2].

In the present study, citizen scientists were involved in long-term monitoring and data collection of behavioural patterns of three model avian species: the greylag goose (Anser anser), the northern bald ibis (Geronticus eremita) and the common raven (Corvus corax). The birds are free flying and individually marked with a unique combination of coloured leg rings (geese, ibises and ravens) or wing tags (ravens). Following on from the long-term monitoring introduced for the geese by Lorenz and his co-workers in 1973, life-history data of the three species has been monitored continuously for many years [3]. Especially during the breeding season (February to July), the birds can be observed in the area of the Cumberland Game Park (47 48' 24,6" $\left.\mathrm{N}, 13^{\circ} 57^{\prime} 2,4^{\prime \prime} \mathrm{O}\right)$ adjacent to the Konrad Lorenz Research Centre. The longstanding and close cooperation between the two institutions offers an excellent opportunity to involve visitors in long-term research generating a win-win situation for all participants. Adults, children and local school classes were invited to participate. Citizen scientists were asked to contribute to the long-term monitoring by identifying the individual bird by its tagging, location and behaviour by 'spotting' the birds using a software application developed for ad hoc observations (Forschen im Almtal, Spotteron, [4]). 
The following questions were addressed: (1) Can citizen scientists be reliable collaborators for the long-term monitoring of the research center? (2) Are the collected data useful for research? (3) Is the use of smartphone apps a good 'means to an end'?

\section{Methods and Results}

A WIFI hotspot set up at the entrance of the game park allowed participants to download the app in advance as well as to upload the collected data at the end of their observations without using their own mobile data. On their walk through the game park (approx. $2 \mathrm{~km}$ ), visitors recorded ring or tag combinations, time and location of sighted birds by uploading them via the app. The researchers offered regular training sessions for interested volunteers. During such training sessions, citizen scientists were informed (1) how to enter the data, (2) how to observe bird behaviour, and (3) how to correctly identify the tags (e.g. left and right, up and down). However, a training was not mandatory to be able to join the project. Citizen scientists submitted observations including GPS location of the spotted bird, a mandatory picture, and a description of the observed behavior and tag (colours, form, and position of the tag). We currently present data collected between October 2017 and March 2019. Within this period a total number of 99 users delivered approximately 1000 sightings (greylag goose: 803, common raven: 164, northern bald ibis: 73).

For the analyses, three major aspects were considered mandatory for the assessment of the reliability of the data and their relevance for research: (1) the position of the sighted focal individual, indicated by the GPS coordinates, had to be located within the study area; (2) the selected behavior of the observed individual had to match the behavior displayed by the animal in the uploaded picture; (3) the indicated tag had to exist in our database and if possible to be visible on the uploaded picture. Sightings meeting the last two requirements were marked by researchers (CS, JR) post-hoc as "Top Spots" to showcase best practice observations. For this purpose and in order to confirm applicability of the data for research, each uploaded sighting was checked by a scientist (CS, JR) before entering analysis. Such an accuracy-assessment task took approximately one minute per sighting and was conducted both manually (location, behavior) and automatically (tag).

The percentages of correct observations were calculated for all the aspects considered and for the three different bird species. In general, the percentages of relevant data were 
very high for all three aspects considered, i.e. (1) the location of the sighting (90\%), (2) the behavior (95\%), and (3) the tag (84\%). However, there were differences in the number of sightings across species, with most sightings of greylag geese (Fig. 1).

\section{Discussion and Conclusions}

Our results suggest that the involvement of citizens in research by mean of digital devices might be a suitable method to acquire long-term data on animal behaviour. However, it is important to consider and not underestimate the time required to check the collected data (in our case the sightings) for accuracy as well as the possible range in accuracy performance among the participants. An extensive training might be useful to reduce the percentage of mistakes and to improve the percentage of useful data for research [5]. In the present study, the researchers offered regular training sessions for interested volunteers. However, mainly school classes took advantage of this opportunity. Marking accurate sightings as "Top Spots" can be considered as a reinforcement for the motivation of the users and at the same time be used as a best practice example for other participants. For the same purpose (fostering the motivation of the participants), the research team joined the Austrian Citizen Science Award and initiated the Wildpark Challenge: both initiatives generated a positive reinforcement outcome for the most accurate participants.

One possible reason for the difference in number of observations collected per species might be that the ground-dwelling greylag goose was easier to spot compared with the often arboreal northern bald ibis and common raven. The greylag goose was the most sighted of the three species, which could be linked with its conspicuous presence in the study area and its tendency to encounter visitors along walking paths that are used by both the visitors and geese. However, such results might also depend on the daily behavioural patterns of the species, with the common ravens and the northern bald ibises using the study area at different times of the day compared to the visitors (e.g. early in the morning). In general school classes were more prone to use the app than the other categories of visitors (families, single persons). Further studies should focus on the reception and reliability in the use of the app by different categories of visitors. Taken together, our findings confirm that an involvement of trained citizens in research projects might be of great relevance for science as well as for the society, as large data 
sets contributing to long-term monitoring are acquired and participants enhance their knowledge and awareness towards nature and science [5]. This results in a win- win outcome for all stakeholders involved: the researchers gain relevant data and the game park can offer special leisure activities associated with knowledge acquisition, which is a unique offering in the region. Our research conclusion concurs with the general conclusion of the Austrian Citizen Science Conference 2019 on "Grenzen und Übergänge": border areas are not only boundaries, but also areas of transition and exchange, as for instance between science and society or researchers and citizen scientists respectively.

\section{Acknowledgments}

We gratefully acknowledge permanent support from the "Herzog von Cumberland Stiftung" and the "Verein der Förderer der Konrad Lorenz Forschungsstelle". Special thanks to J. Hemetsberger, B. Lankmaier (Cumberland Wildpark) and P. Hummer (Spotteron) for their valuable support. Financial support was provided by the following third party fundings: FFG Nr. 858551 (to DF and CS); BMWF-TCS 02/06 (to VPS); BMWF-SPA 06/155 (to JR).

\section{References}

[1] Hecker S., Haklay M., Bowser A., Makuch Z., Vogel J. and A. Bonn. Citizen Science - Innovation in Open Science, Society and Policy. UCL Press, London, 2018.

[2] Ceccaroni L., J. and Piera. Analyzing the Role of Citizen Science in Modern Research. Hershey, Pennsylvania (USA): ICI Global, 2017.

[3] Hemetsberger J., Weiß B.M., and I.B.R. Scheiber. Greylag Geese: from general principles to the Konrad Lorenz flock, in The social life of Greylag Geese. Patterns, mechanisms and evolutionary function in an avian model system, ed. IBR Scheiber, BM Weiss, J Hemetsberger, K Kotrschal (Cambridge: Cambridge University Press), 3-25, 2013.

[4] Spotteron; Forschen im Almtal, https://www.spotteron.com/forschenimalmtal/info Last recover Jan., $11^{\text {th }}, 2020$

[5] Frigerio D., Pipek P., Kimmig S., Winter S., Melzheimer J., Diblíková L., Wachter B., and A. Richter. Citizen science and wildlife biology: Synergies and challenges. Ethology, 4, e6968. doi.org/10.1155/2012/710710, 2018. 


\section{Legend to Figure 1:}

Percentages of correct observations (applicable data) for the three species considered. The reported sightings were checked for correctness of both aspects, species and tag identification. 